\title{
Divergência genética entre linhagens de melão pele de Sapo $^{1}$
}

\author{
Genetic divergence among Piel Del Sapo melon lines
}

\author{
Glauber Henrique de Sousa Nunes²*, José Hamilton da Costa Filho³, Derly José Henriques Silva ${ }^{4}$, Pedro \\ Crescêncio Souza Carneiro ${ }^{5}$ e Mara Suyane Marques Dantas ${ }^{3}$
}

\begin{abstract}
Resumo - Estudou-se a divergência genética entre linhagens de melão pele de Sapo, avaliadas em Mossoró-RN. Foram avaliadas vinte linhagens em um experimento em blocos casualizados com três repetições. A divergência genética foi avaliada por procedimentos multivariados: distância generalizada de Mahalanobis, método de agrupamento de otimização de Tocher e UPGMA. As características estudadas foram: número total de frutos, produtividade, peso médio dos frutos, diâmetro transversal, diâmetro longitudinal, índice de formato, cavidade interna, espessura da polpa, firmeza da polpa, teor de sólidos solúveis, concentração de colheita e perda de peso. Houve concordância parcial quanto à composição dos grupos formados pelos métodos de otimização de Tocher e UPGMA. As características que mais contribuíram para a divergência foram firmeza de polpa $(20,69 \%)$ e sólidos solúveis $(10,94 \%)$. A presença de variabilidade genética permitiu a identificação de cultivares dissimilares e com média elevada para as características estudadas. Os cruzamentos sugeridos no estudo da divergência genética foram: SA-13 x TH-03, SA-13 x TH-04, SA-13 x TH-05, SA-13 x TH-07, SA-13 x TH-09 e SA-13 x SA-17, TH-05 x TH-04, TH-05 x SA-10, TH-05 x SA-12, TH-05 x SA-14 e TH-05 x SA-14.
\end{abstract}

Palavras-chave - Cucumis melo. Escolha de genitores. Heterose. Cucumis melo - Variabilidade genética.

\begin{abstract}
The objective of this work was to study the genetic divergence among lines of Pele de Sapo melon evaluated in Mossoró-RN, Brazil. Twenty lines were evaluated in a randomized block design with three replications. The genetic divergence was evaluated by multivariate procedures: generalized distance of Mahalanobis, methods of grouping optimization of Tocher and UPGMA. The traits assessed were: The traits evaluated were: total number of fruits, productivity, average weight of fruits, transversal diameter, diameter longitudinal, format index, internal cavity, pulp thickness, pulp firmness, soluble solids content, concentration of harvesting and weight loss. There was partial concordance regarding the composition of the groups formed by the methods of optimizing Tocher and UPGMA. The traits that most contributed to the divergence have been pulp firmness $(20.69 \%)$ and soluble solids (10.94\%). The presence of genetic variability allowed the identification of cultivars dissimilar and with a mean high for the traits studied. The crosses suggested in the study of genetics divergence were: SA-13 x TH-03, SA-13 x TH-04, SA-13 x TH-05, SA-13 x TH-07, SA-13 x TH-09, SA-13 x SA-17, TH-05 x TH-04, TH-05 x SA-10, TH-05 x SA-12, TH-05 x SA-14 and TH-05 x SA-14.
\end{abstract}

Key words - Cucumis melo. Choice of parents. Heterosis. Cucumis melo - Genetic variability.

\footnotetext{
*Autor para correspondênca

${ }^{1}$ Recebido para publicação em 08/09/2010; aprovado em 20/04/2011

Pesquisa financiada com recursos do PROAP (CAPES)

2Departamento de Ciências Vegetais/UFERSA, Av. Francisco Mota, Campus Mossoró, Mossoró-RN, Brasil, glauber@ufersa.edu.br

${ }^{3}$ Programa de pós-graduação em fitotecnia com área de concentração em melhoramento vegetal/UFERSA, Av. Francisco Mota, Campus Mossoró, Mossoró-RN, Brasil, 59.625-900, hamilton costa@yahoo.com.br,mra suy@hotmail.com

${ }_{4}^{4}$ Departamento de Fitotecnia, UFV, Av. PH Rolfs, s/n, Campus Universitário, Visçosa-MG, Brasil, 36.571-000, derly@mail.ufv.br

${ }_{5}^{5}$ Departamento de Biologia Geral, Av. P.H. Rolfs, s/n, Campus Universitário, Viçosa-MG, Brasil, 36.571-000, carneiro@ufv.br
} 


\section{Introdução}

A lavoura meloeira é baseada no uso de sementes melhoradas, em especial, híbridos simples, bem como na alta tecnologia de produção com a aplicação de insumos agrícolas e modernas técnicas de irrigação e manejo pós-colheita dos frutos (FREITAS et al., 2007). Dentre os híbridos existentes, aqueles pertencentes à variedade botânica inodorus são os mais cultivados, com destaque para o tipo amarelo que corresponde a mais de $60 \%$ do melão exportado, seguido dos tipos Orange Flesh com 15,1\% das exportações e Pele de Sapo com 9,29\%, sendo este último preferido no mercado espanhol (SALES JÚNIOR et al., 2006).

A maioria dos híbridos produzidos são oriundos de programas de melhoramento desenvolvidos em países como os Estados Unidos, Espanha, Holanda e França. Os genótipos selecionados e produzidos nesses países são avaliados pelos produtores em áreas de cultivo comercial. Todavia, nos últimos anos, tanto as empresas privadas como as empresas públicas têm desenvolvido trabalhos de melhoramento nas condições climáticas e de cultivo dos principais Estados produtores como Rio Grande do Norte e Ceará.

A estratégia é a obtenção de linhagens endogâmicas, com recuperação da heterose por cruzamentos. Por outro lado, no caso, principalmente, de instituições públicas, nas quais os recursos são limitados, a obtenção de híbridos simples de todas as linhagens selecionadas pode ser um fator limitante. Com efeito, o conhecimento da divergência genética entre os possíveis genitores tem sido bastante importante para estudos que envolvem hibridações, pois fornecem informações para a identificação de genitores que possibilitem maior efeito heterótico. A divergência genética tem sido utilizada como indicativo de que os genitores quando cruzados proporcionarão elevado efeito heterótico aos seus híbridos (CRUZ et al., 1994).

No estudo da divergência genética, empregam-se procedimentos multivariados de análise estatística com o intuito de reunir, por algum critério de classificação, as unidades amostrais em vários grupos, de tal forma que exista homogeneidade dentro de cada grupo e heterogeneidade entre grupos (MACHADO et al., 2002).

Embora existam muitos artigos de diversidade com o meloeiro na literatura internacional, em especial como marcadores moleculares (LOPÉZ-SESÉ et al., 2003; STAUB et al., 2003), no Brasil, ainda são escassos os trabalhos com divergência genética. Rizzo e Braz (2004), utilizando a distância de Mahalanobis obtida por caracteres morfológicos, agruparam cinco linhagens de melão rendilhado em dois grupos. $\mathrm{O}$ primeiro grupo formado pelas linhagens JAB-20, JAB-21 e 'Bônus 02', e o segundo, por JAB-22 e JAB-23. Braz et al. (2004), avaliando a divergência genética de vinte linhagens de melão rendilhado por características morfológicos, obtiveram pela técnica de otimização de Tocher, sete grupos de similaridade, sendo um formado por 14 genótipos e seis formados por um genótipo cada.

Diante dessas considerações, o presente trabalho foi desenvolvido para quantificar a dissimilaridade genética entre linhagens de melão Pele de Sapo a partir de características morfo-agronômicas, por meio da aplicação de estatística multivariada, visando indicar cruzamentos potencialmente promissores.

\section{Material e métodos}

O experimento foi conduzido entre setembro e novenbro de 2005 em Mossoró, município do Rio Grande do Norte, situado a $5^{\circ} 11^{\prime}$ de latitude Sul, $37^{\circ} 20^{\prime}$ longitude a oeste de Greenwich e $18 \mathrm{~m}$ de altitude. O clima, segundo a classificação de Koppen, é BSwh', ou seja, muito seco, com estação de chuva no verão atrasando-se para o outono (período de março a junho) (CARMO FILHO; OLIVEIRA, 1989).

Foram avaliadas 20 linhagens pele de Sapo, sendo as linhagens TH-01, TH-02, TH-03, TH-04, TH-05, TH06, TH-07, TH-08, TH-09 obtidas do cruzamento entre os híbridos do Tipo Pele de Sapo HTH-07 e Tendency. As linhagens SA-10, SA-11, SA-12, SA-13, SA-14, SA-15, SA-16, SA-17, SA-18, SA-19 e SA-20, obtidas do híbrido do tipo Pele de Sapo Sancho. Todas as linhagens do presente estudo têm polpa branca e expressão sexual andromonóica. As linhagens foram obtidas pelo método SSD (Single Seed Descendent) com modificações e estão na geração $\mathrm{S}_{8}$.

A cultura foi irrigada por gotejamento, com fertirrigação, no espaçamento de 2,0 m entre linhas e $0,5 \mathrm{~m}$ entre gotejadores. Foram utilizados dois turnos de rega no período entre 12 e 30 dias após o transplantio e um turno de rega até 65 dias. No manejo da irrigação, a evapotranspiração da cultura foi estimada a partir da evapotranspiração de referência, através da equação de Penman-Monteith FAO utilizando dados de uma estação climatológica situada a $12 \mathrm{~km}$ e coeficiente de cultura $(\mathrm{Kc})$. A lâmina total de irrigação foi obtida pela razão entre a evapotranspiração da cultura e a eficiência da irrigação, adotada como 0,91 . O volume de água foi em torno de $3.000 \mathrm{~m}^{3} \mathrm{ha}^{-1}$. Os fertilizantes foram aplicados de acordo com as recomendações baseadas na análise do solo. A adubação de fundação, em $\mathrm{kg} \mathrm{ha}^{-1}$, consistiu de $130 \mathrm{~N}, 270$ $\mathrm{K}_{2} \mathrm{O}$ e 85 de $\mathrm{P}_{2} \mathrm{O}_{5}$ e $10 \mathrm{t} \mathrm{ha}^{-1}$ de esterco bovino. As fontes de minerais fornecidas via água de irrigação, em $\mathrm{kg} \mathrm{ha}^{-1}$, foram: 450 de $\mathrm{KCl}, 120$ de Uréia, 450 de $\mathrm{CaNO}_{3}$ e 210 de $\mathrm{H}_{3} \mathrm{PO}_{4}$. As demais práticas culturais foram realizadas conforme a recomendação de manejo para a cultura no estado (NUNES et al., 2005). 
Utilizou-se o delineamento de blocos completos casualizados com três repetições. Cada parcela foi constituída por duas linhas de 5 metros de comprimento, contendo 10 plantas cada. As características avaliadas estão apresentadas na Tabela 1. A metodologia de avaliação das características está descrita em detalhes por Torres et al. (2009).

Foram realizadas análises de variância univariada para todas as características avaliadas e, posterior agrupamento de médias conforme Scott-Knott (BHERING et al., 2008). Posteriormente, realizou-se a análise de variância multivariada e aplicação do critério de Wilks a $5 \%$ de significância. A partir da matriz das médias de cada característica para cada linhagem e da matriz de variância-covariância residual, foram calculadas as distâncias generalizadas de Mahalanobis $\left(\mathrm{D}_{\mathrm{ij}}^{2}\right)$, conforme descrição de Cruz et al. (2004). Realizouse o diagnóstico de multicolinearidade da matriz de correlação residual pelo método de Montgomery e Peck (1981). A análise de agrupamento foi realizada com a matriz de distâncias de Mahalanobis entre as linhagens, utilizando o método aglomerativo de Tocher e o método hierárquico do UPGMA. Foi utilizado o critério de Singh, descrito por Cruz et al. (2004), para identificar a contribuição relativa de cada característica para a divergência genética. Todas as análises foram processadas no programa GENES (CRUZ, 2008).

\section{Resultados e discussão}

A existência de diferenças significativas entre as médias dos cultivares para todas as características, exceto diâmetro transversal, concentração de colheita e perda de peso, ao nível de $1 \%$ de significância pelo teste $\mathrm{F}$ de Snedecor, indicando a existência de variabilidade genética estão apresentados na Tabela 1.

As linhagens foram agrupadas em três grupos, conforme metodologia de Scott-Knott, para o número total de frutos (TAB. 1). As linhagens com maior número de frutos, primeiro grupo, foram $\mathrm{TH}-02$, $\mathrm{TH}-08, \mathrm{SA}-10$ e SA20. Enquanto que as linhagens TH-03, TH-05, TH-07, TH09, SA-13 e SA-15, pertencentes ao grupo três, possuíram os menores valores da referida característica. $\mathrm{O}$ número de frutos é uma característica importante dentro de um programa de melhoramento do meloeiro. Considerando que o mercado exige frutos pesados $(\geq 3,0 \mathrm{~kg})$ de melão do tipo Pele de Sapo, o melhorista deve priorizar frutos maiores, contudo deve selecionar genótipos produtivos. Sabendo que o número de frutos é uma característica que se correlaciona positivamente com a produtividade, mas negativamente com o tamanho do fruto (NUNES et al., 2009) é sempre um desafio para o melhorista. Nos hibridos atuais, em média, são colhidos 1,5 frutos por planta no padrão comercial.
Com relação à produtividade, também foi verificada a formação de três grupos. O primeiro grupo, formado pelas mais produtivas, contemplou $70 \%$ das linhagens, sendo as linhagens TH-01, TH-02, TH-04, TH06 e TH-08 do cruzamento dos híbridos do tipo Pele de Sapo HTH-07 e Tendency; e as demais linhagens (SA-10, SA-12, SA-14, SA-15, SA-16, SA-17, SA-18, SA-19 e SA-20) do híbrido Sancho. O segundo grupo foi composto pelas linhagens $\mathrm{TH}-03$, TH-07 e SA-11, enquanto que o terceiro foi constituído pelas linhagens TH-05, TH09 e SA-13. Em melão, a produtividade precisa ser de pelos menos $25 \mathrm{t} \mathrm{ha}^{-1}$ para que o produtor tenha lucro (PAIVA et al., 2002). Assim sendo, apenas as linhagens pertencentes ao primeiro grupo estariam próximas desse nível mínimo. Um aspecto importante a ser ressaltado é que como se trata de linhagens, as médias são inferiores àquelas observadas nos híbridos avaliados em estudos anteriores no Agropolo Mossoró-Assu (NUNES et al., 2004; NUNES et al., 2005). Por outro lado, segundo Dias et al. (1998), a produtividade média de melão está entre 17 e $30 \mathrm{t} \mathrm{ha}^{-1}$. Com efeito, a média do experimento está dentro da faixa verificada pelos autores. Outro aspecto relevante na cultura do meloeiro é que a mesma possui pouca depressão por endogamia, assim como as demais cucurbitáceas, sendo na verdade considerada uma espécie mista quanto à biologia reprodutiva (MALUF, 2001). Esse fato é muito relevante, pois indica a possibilidade de obter cultivares de melão como linhagens, embora as empresas privadas tenham explorado a heterose, lançando anualmente no mercado apenas híbridos simples por diversas razões, inclusive de proteção comercial. A exceção são as variedades de polinização aberta de melão do tipo Honey Dew (GUSMINI et al., 2008).

Formaram-se três grupos quanto ao peso médio do fruto, sendo o primeiro grupo formado pelas linhagens TH-01, TH-05, SA-13, SA-15, SA-16 e SA-19, com frutos superiores a $3,0 \mathrm{~kg}$. O tamanho do fruto do melão do tipo Pele de Sapo é uma característica muito importante uma vez que, ao contrário dos frutos de todos os outros tipos de melão, o mercado consumidor exige frutos de melão do tipo Pele de Sapo com tamanhos acima de 3,0 kg. Não obstante, o melão Pele de Sapo é muito apreciado principalmente no mercado espanhol, sendo comercializados, no Porto de Natal, frutos entre 2,5 e 3,5 kg (SALES JÚNIOR et al., 2006). Com efeito, os frutos das linhagens do segundo grupo também podem ser comercializados no mercado europeu.

As linhagens não diferiram quanto ao diâmetro transversal, embora tenham diferido quanto ao diâmetro transversal. Para a referida característica formaram-se três grupos de linhagem. O grupo de menores médias foi composto pelas linhagens TH-06 e TH-08. O segundo grupo foi formado pelas linhagens TH-02, TH-04 e AS-10. Por fim, o grupo com frutos mais alongados foi composto pelas demais linhagens. 
Tabela 1 - Médias de doze características de linhagens de melão pele de Sapo avaliadas em Mossoró-RN. Mossoró-RN, 2005

\begin{tabular}{|c|c|c|c|c|c|c|c|c|c|c|c|c|}
\hline \multirow{2}{*}{ Linha } & \multicolumn{12}{|c|}{ Médias (Características) } \\
\hline & NTF & PROD & PMF & DT & $\mathrm{DL}$ & IF & $\mathrm{CI}$ & EP & FP & SST & $\mathrm{CC}$ & $\mathrm{PP}$ \\
\hline TH-01 & $13.709 b$ & $27,10 \mathrm{a}$ & $3,44 a$ & $17,2 \mathrm{a}$ & $22,6 a$ & $1,3 a$ & $6,5 \mathrm{a}$ & $4,3 \mathrm{a}$ & $32,2 \mathrm{c}$ & $11,2 \mathrm{~b}$ & $50,8 \mathrm{a}$ & $2,7 \mathrm{a}$ \\
\hline TH-02 & $19.091 \mathrm{a}$ & $20,80 \mathrm{a}$ & $2,02 \mathrm{c}$ & $15,1 \mathrm{a}$ & $18,0 \mathrm{~b}$ & $1,2 b$ & $6,3 b$ & $3,7 \mathrm{~b}$ & $32,3 c$ & $11,0 \mathrm{c}$ & $47,2 \mathrm{a}$ & $2,7 \mathrm{a}$ \\
\hline TH-03 & $9.432 \mathrm{c}$ & $18,01 \mathrm{~b}$ & $2,62 \mathrm{c}$ & $16,4 \mathrm{a}$ & $21,6 \mathrm{a}$ & $1,3 \mathrm{a}$ & $6,6 a$ & $4,0 \mathrm{~b}$ & $23,5 d$ & $9,1 \mathrm{~d}$ & $53,2 \mathrm{a}$ & $2,9 a$ \\
\hline TH-04 & $14.135 b$ & $23,97 \mathrm{a}$ & $2,46 \mathrm{c}$ & $16,2 \mathrm{a}$ & $18,2 b$ & $1,1 \mathrm{c}$ & $6,8 \mathrm{a}$ & $3,9 b$ & $38,0 \mathrm{~b}$ & $10,5 \mathrm{c}$ & $45,4 \mathrm{a}$ & $2,6 \mathrm{a}$ \\
\hline TH-05 & $7.070 \mathrm{c}$ & $12,95 \mathrm{c}$ & $3,03 \mathrm{a}$ & $17,4 \mathrm{a}$ & $21,4 \mathrm{a}$ & $1,2 \mathrm{~b}$ & $6,3 b$ & $4,5 \mathrm{a}$ & $18,8 \mathrm{e}$ & $9,5 \mathrm{~d}$ & $52,1 \mathrm{a}$ & $3,1 \mathrm{a}$ \\
\hline TH-06 & $14.865 b$ & $24,93 \mathrm{a}$ & $2,25 \mathrm{c}$ & $16,3 \mathrm{a}$ & $17,1 \mathrm{c}$ & $1,1 \mathrm{c}$ & $6,8 \mathrm{a}$ & $4,0 \mathrm{~b}$ & $29,1 \mathrm{c}$ & $10,2 \mathrm{c}$ & $47,6 \mathrm{a}$ & $2,9 a$ \\
\hline TH-07 & $7.357 \mathrm{c}$ & $19,18 b$ & $2,46 c$ & $15,9 \mathrm{a}$ & $20,9 a$ & $1,3 a$ & $5,2 b$ & $4,6 a$ & $24,6 \mathrm{~d}$ & $8,8 \mathrm{~d}$ & $47,1 \mathrm{a}$ & $3,2 \mathrm{a}$ \\
\hline TH-08 & $22.661 \mathrm{a}$ & $22,47 \mathrm{a}$ & $2,35 c$ & $15,2 \mathrm{a}$ & $16,3 c$ & $1,1 \mathrm{c}$ & $5,9 b$ & $3,6 b$ & $32,6 \mathrm{c}$ & $11,9 b$ & $48,3 \mathrm{a}$ & $3,0 \mathrm{a}$ \\
\hline ТH-09 & $7.597 \mathrm{c}$ & $12,09 \mathrm{c}$ & $2,64 \mathrm{c}$ & $16,3 \mathrm{a}$ & $22,4 \mathrm{a}$ & $1,4 \mathrm{a}$ & $7,1 \mathrm{a}$ & $3,9 b$ & $25,3 d$ & $8,7 \mathrm{~d}$ & $43,1 \mathrm{a}$ & $2,5 \mathrm{a}$ \\
\hline SA-10 & $19.032 \mathrm{a}$ & $24,50 \mathrm{a}$ & $2,31 \mathrm{c}$ & $16,1 \mathrm{a}$ & $18,9 b$ & $1,2 \mathrm{~b}$ & $7,4 \mathrm{a}$ & 5,00 & $38,8 \mathrm{~b}$ & $11,5 b$ & $45,7 \mathrm{a}$ & $3,1 \mathrm{a}$ \\
\hline SA-11 & $9.543 \mathrm{c}$ & $16,32 b$ & $2,87 b$ & $16,0 \mathrm{a}$ & $22,8 \mathrm{a}$ & $1,4 \mathrm{a}$ & $6,1 b$ & $4,3 \mathrm{a}$ & $30,1 \mathrm{c}$ & $12,6 b$ & $46,1 \mathrm{a}$ & $3,3 \mathrm{a}$ \\
\hline SA-12 & $14.106 \mathrm{~b}$ & $22,55 \mathrm{a}$ & $2,89 b$ & $16,7 \mathrm{a}$ & $23,3 \mathrm{a}$ & $1,4 a$ & $6,8 \mathrm{a}$ & $4,3 \mathrm{a}$ & $31,2 \mathrm{c}$ & $14,4 \mathrm{a}$ & $47,0 \mathrm{a}$ & $2,9 a$ \\
\hline SA-13 & $6.860 \mathrm{c}$ & $11,90 \mathrm{c}$ & $3,10 \mathrm{a}$ & $17,3 \mathrm{a}$ & $24,2 \mathrm{a}$ & $1,4 a$ & $6,9 a$ & $4,5 \mathrm{a}$ & $44,4 \mathrm{a}$ & $12,6 b$ & $47,7 \mathrm{a}$ & $2,7 \mathrm{a}$ \\
\hline SA-14 & $14.344 \mathrm{~b}$ & $21,70 \mathrm{a}$ & $2,72 b$ & $17,0 \mathrm{a}$ & $23,6 \mathrm{a}$ & $1,4 a$ & $5,9 b$ & $5,1 \mathrm{a}$ & $32,2 \mathrm{c}$ & $11,8 b$ & $47,2 \mathrm{a}$ & $3,1 \mathrm{a}$ \\
\hline SA-15 & $11.313 \mathrm{c}$ & $22,13 a$ & $3,09 a$ & $18,1 \mathrm{a}$ & $23,2 \mathrm{a}$ & $1,3 a$ & $6,6 a$ & $4,5 \mathrm{a}$ & $26,7 \mathrm{~d}$ & $11,8 \mathrm{~b}$ & $43,8 \mathrm{a}$ & $2,7 \mathrm{a}$ \\
\hline SA-16 & $12.658 b$ & $21,70 \mathrm{a}$ & $3,10 \mathrm{a}$ & $16,6 \mathrm{a}$ & $22,7 \mathrm{a}$ & $1,4 a$ & $6,5 \mathrm{a}$ & $4,2 \mathrm{a}$ & $31,3 c$ & $12,0 \mathrm{~b}$ & $52,1 \mathrm{a}$ & $3,0 \mathrm{a}$ \\
\hline SA-17 & $14.993 b$ & $23,83 a$ & $2,77 \mathrm{~b}$ & $17,0 \mathrm{a}$ & $22,5 \mathrm{a}$ & $1,4 a$ & $6,6 a$ & $4,2 \mathrm{a}$ & $22,6 \mathrm{~d}$ & $12,8 \mathrm{~b}$ & $48,1 \mathrm{a}$ & $2,8 \mathrm{a}$ \\
\hline SA-18 & $14.210 \mathrm{~b}$ & $21,70 \mathrm{a}$ & $2,75 b$ & $16,0 \mathrm{a}$ & $22,5 \mathrm{a}$ & $1,4 a$ & $6,3 b$ & $4,1 \mathrm{a}$ & $24,2 d$ & $13,3 \mathrm{a}$ & $47,3 \mathrm{a}$ & $3,2 \mathrm{a}$ \\
\hline SA-19 & $16.909 \mathrm{~b}$ & $22,36 \mathrm{a}$ & $3,16 \mathrm{a}$ & $16,9 \mathrm{a}$ & $22,7 \mathrm{a}$ & $1,4 a$ & $6,1 b$ & 4,6a & $30,1 \mathrm{c}$ & $13,4 \mathrm{a}$ & $55,6 \mathrm{a}$ & $2,4 \mathrm{a}$ \\
\hline SA-20 & $21.774 \mathrm{a}$ & $26,67 \mathrm{a}$ & $2,89 b$ & $15,9 \mathrm{a}$ & $22,3 \mathrm{a}$ & $1,4 \mathrm{a}$ & $5,6 \mathrm{~b}$ & $4,5 \mathrm{a}$ & $30,0 \mathrm{c}$ & $13,9 \mathrm{a}$ & $47,9 \mathrm{a}$ & $2,6 \mathrm{a}$ \\
\hline Media & 13.583 & 20843 & 2745 & 16,5 & 21,4 & 1,3 & 6,4 & 4,2 & 29,9 & 11,5 & 48,2 & 2,9 \\
\hline $\mathrm{Fc}$ & $4,5^{* *}$ & $7,5^{* *}$ & $2,9 * *$ & $0,9^{\text {ns }}$ & $15, * *$ & 19,5 & $3,1 * *$ & $3,3 * *$ & $39,9 * *$ & $9,8 * *$ & $0,7^{\mathrm{ns}}$ & $0,8^{\mathrm{ns}}$ \\
\hline $\mathrm{CV}(\%)$ & 28,6 & 15,4 & 8,9 & 5,4 & 4,9 & 3,8 & 8,1 & 8,6 & 9,6 & 8,1 & 13,3 & 16,8 \\
\hline
\end{tabular}

Médias seguidas pela mesma letra pertencem ao mesmo grupo pelo teste de Scott-Knott a 5\% de significância. NTF: número total de frutos por ha; PROD: produtividade ( $\left.\mathrm{t} \mathrm{ha}^{-1}\right)$; PMF: peso médio do fruto $(\mathrm{kg})$; DT: diâmetro transversal (cm); DL: diâmetro longitudinal (cm); IF: índice de formato; CI: cavidade interna $(\mathrm{cm})$; EP: espessura da polpa $(\mathrm{N})$; SST: teor de sólidos solúveis totais (\%); CC: concentração de colheita (\%); PP: perda de peso $(\%) . \mathrm{F}_{\mathrm{c}}$ : Estimativa $\mathrm{F}$ de Snedecor. **: Significativo ao nível 1\%. ns: não significativo

Houve maior discriminação entre as linhagens oriundas dos genitores THT-07 e Tendency, quando comparadas com as linhagens oriundas do híbrido Sancho.

Para o índice de formato verificou-se exatamente a mesma discriminação observada para o diâmetro longitudinal (TAB. 1). Todas as linhagens têm frutos de formato oval $(1,01<\mathrm{IF}<1,50)$ (PAIVA et al., 2000), característica marcante dos cultivares de melão do tipo Pele de Sapo.

As linhagens foram agrupadas em dois grupos quanto à cavidade interna. $\mathrm{O}$ grupo com as menores estimativas de médias foi formado pelas linhagens TH-02, TH-05, TH-08, SA-11, SA-14, SA-18, SA-19 e SA-20. As linhagens também foram divididas em dois grupos para a espessura da polpa. O grupo com maiores estimativas foi constituído por $65 \%$ das linhagens, com estimativas variando de 4,4 a 5,1 cm. No melão é desejado fruto com menor cavidade interna e maior espessura da polpa, pois tais características reduzem o deslocamento da placenta, desacelerando a deterioração do fruto. Os valores médios observados estão coerentes com as estimativas observadas em híbridos de melão do tipo Pele de Sapo, cultivados no Estado do Rio Grande do Norte (NUNES et al., 2005).

Verificou-se uma grande discriminação de linhagens para firmeza da polpa, com a formação de cinco grupos. Todavia, a maioria das linhagens foi agrupada nos três grupos intermediários. Os grupos extremos foram formados cada um por apenas uma linhagem. A linhagem SA-13 o grupo de maior média (44 N), enquanto que a linhagem TH-05 formou o grupo de menor média $(18,8 \mathrm{~N})$. A firmeza da polpa é outro atributo de qualidade importante, 
em razão dos frutos com maior firmeza serem mais resistentes às injúrias mecânicas durante o transporte $\mathrm{e}$ a comercialização. Frutos colhidos com maior firmeza da polpa têm, geralmente, maior conservação e vida útil pós-colheita. Em estudos realizados com vários tipos de melão no Agropólo Mossoró-Assu, Filgueiras et al. (2000) observaram o valor mínimo de $22 \mathrm{~N}$ para firmeza da polpa. No presente trabalho, apenas a linhagem TH-05 tem firmeza da polpa abaixo do valor mínimo.

As linhagens foram agrupadas em quatro grupos para o teor de sólidos solúveis. Destaque para as linhagens dos dois primeiros grupos, com estimativas superiores a 10\%. O teor de sólidos solúveis (SST), definido como a percentagem de sólidos solúveis no suco extraído da polpa, é um fator tradicionalmente usado para definir a qualidade do melão. A maioria dos países utiliza os valores do conteúdo de sólidos solúveis como o principal guia de mercado para a aceitação de frutos do meloeiro. O valor mínimo recomendado para Europa para o melão Pele de Sapo, segundo Filgueiras et al. (2000) é de 11\%. Conforme este critério, apenas as linhagens dos dois primeiros grupos estariam dentro do valor mínimo aceitável. Não obstante, frutos com valores acima de 10\% têm sido comercializados no porto de Natal (SALES JÚNIOR et al., 2006).

Em melão é interessante que a maioria dos frutos seja colhida na primeira, ou pelo menos, na segunda colheita, pois reduz as atividades de colheita, no campo, e pós-colheita, em packing house, diminuindo os custos de produção com mão-de-obra. Outro aspecto não menos relevante é o fato de que frutos colhidos nas últimas colheitas podem ser afetados pelo estresse causado nas plantas devido às atividades das colheitas anteriores. As linhagens não diferiram quanto à concentração de colheita. As porcentagens observadas estão dentro da faixa constatada em híbridos comerciais no Agropolo Mossoró-Assu.

Durante o período de armazenamento, uma característica importante a ser analisada é a perda de massa, ocasionada pela transpiração dos frutos. A perda de massa pode acarretar sérios efeitos sobre as propriedades físicas, nutricionais, fisiológicas, patológicas e de aparência do produto. Em adição, do ponto de vista econômico, a perda de peso é uma característica fundamental, pois a venda dos frutos é feita em unidade de massa. As linhagens não diferiram quanto a essa característica. Não houve efeito de linhagens e os valores observados estão de acordo com as estimativas observadas em estudos de pós-colheita realizados na região (GOMES JÚNIOR et al., 2001; MENEZES et al, 2001).

Considerando as distâncias máxima e mínima para cada uma das linhagens avaliadas no presente estudo (TAB. 2), observou-se que a linhagem SA-13 foi a mais divergente em relação a quatorze linhagens
(TH-01, TH-02, TH-03, TH-05, TH-06, TH-07, TH-08, TH-09, SA-11, SA-15, SA-16, SA-17, SA-18 e SA-19), enquanto a linhagem TH-05 em relação a seis linhagns (TH-04, SA-10, SA-12, SA-13, SA-14 e SA-20).

Com relação aos pares menos divergentes, constatou-se que o par mais similar é SA-11 e SA-16 (TAB. 2). De um modo geral, as menores distâncias foram observadas dentro de cada grupo de linhagens, ou seja, as linhagens oriundas do cruzamento THT-04 e Tendency foram mais similares entre si, fato também verificado para as linhagens com background do híbrido Sancho.

No método de UPGMA foram formados quatro grupos (FIG. 1). O primeiro grupo foi formado pela linhagem SA-13; o segundo pelas linhagens TH-06, SA-10, TH-04, TH-08 e TH-02; o terceiro grupo pelas linhagens TH-03, TH-05, TH-07 e TH-09. O quarto grupo foi formado pelas demais linhagens. A correlação cofenética entre matriz de distâncias originais e a matriz resultante do agrupamento foi de $0,76^{* *}$ e a distorção de $15,16 \%$, evidenciando que o agrupamento refletiu as distâncias originais.

Os grupos II e III foram constituídos pelas linhagens oriundas do cruzamento Tendency x HPS-07, com exceção da linhagem SA-10, com background do híbrido Sancho. O grupo IV foi composto por nove linhagens obtidas do híbrido Sancho e apenas uma linhagem do cruzamento Tendency x HPS-07 (FIG. 1).

No presente estudo, firmeza da polpa e sólidos solúveis foram as características que mais contribuíram para a divergência com 20,69 e 10,94\%, respectivamente (TAB. 3). Paiva (2002) e Rizzo e Braz (2002) constataram que o teor de sólidos solúveis foi uma das características de maior contribuição para a divergência genética entre linhagens de melão. Uma das prioridades em qualquer programa de melhoramento é o aumento do teor de sólidos solúveis. Essa é um das características mais importantes no melão, pois é utilizada como um fator de qualidade do fruto. Em função, principalmente, do teor de sólidos solúveis é definido o mercado de consumo do fruto. Por outro lado, a firmeza da polpa está estreitamente relacionada com a vida útil pós-colheita do fruto, sendo uma característica fundamental em frutos exportados para mercados distantes como Europa e Estados Unidos.

A formação de grupos linhagens via Tocher auxilia no planejamento das combinações híbridas a serem obtidas. Com efeito, híbridos promissores podem ser obtidos entre linhagens de grupos distintos. Dentro de cada grupo devem ser identificadas as linhagens de interesse a partir das estimativas das médias das características mais importantes do meloeiro.

A técnica de otimização de Tocher discriminou quatro grupos de linhagens (TAB. 3). O primeiro grupo foi composto 
Tabela 2 - Estimativas das distâncias de Mahalanobis (D2) máxima e mínima de linhagens de melão pele de Sapo avaliadas no município de Mossoró. Mossoró-RN, 2005

\begin{tabular}{ccccc}
\hline \multirow{2}{*}{ Linhagem } & Distância & Linhagem & Distância & Linhagem \\
\cline { 2 - 5 } & 178,70 & SA-13 & 14,84 & SA-16 \\
TH-01 & 194,08 & SA-13 & 21,92 & TH-08 \\
TH-02 & 390,82 & SA-13 & 22,11 & TH-07 \\
TH-03 & 245,14 & TH-05 & 20,64 & SA-09 \\
TH-04 & 545,96 & SA-13 & 28,68 & TH-03 \\
TH-05 & 340,82 & SA-13 & 43,19 & TH-02 \\
TH-06 & 336,98 & SA-13 & 22,11 & TH-03 \\
TH-07 & 261,23 & SA-13 & 21,92 & TH-02 \\
TH-08 & 423,82 & SA-13 & 24,32 & TH-03 \\
TH-09 & 323,52 & TH-05 & 20,63 & TH-04 \\
SA-10 & 174,50 & SA-13 & 10,92 & SA-16 \\
SA-11 & 231,27 & TH-05 & 40,41 & SA-14 \\
SA-12 & 545,96 & TH-05 & 113,38 & SA-09 \\
SA-13 & 207,84 & TH-05 & 25,42 & SA-11 \\
SA-14 & 262,23 & SA-13 & 22,30 & SA-17 \\
SA-15 & 178,42 & SA-13 & 10,92 & SA-11 \\
SA-16 & 310,64 & SA-13 & 12,79 & SA-18 \\
SA-17 & 246,26 & SA-13 & 12,79 & SA-17 \\
SA-18 & 177,46 & SA-13 & 17,74 & SA-20 \\
SA-19 & 199,92 & TH-05 & 17,74 & SA-19 \\
SA-20 & & & & \\
\hline
\end{tabular}

por $70 \%$ das linhagens, sendo nove linhagens SA (SA-17, SA-18, SA-15, SA-16, SA-11, SA-19, SA-12, SA-20 e SA-14) e cinco TH (TH-01, TH-02, TH-07, TH-03, TH-09).

O segundo grupo foi constituído por quatro linhagens, sendo três do cruzamento Tendency $\mathrm{x}$ HTC-07 (TH-04, TH-06 e TH-08) e uma do híbrido Sancho (SA-10). Os grupos III e IV foram compostos por apenas uma linhagem. A linhagem TH-05 no grupo III e a linhagem SA-13, no grupo IV.

Considerando o grupo de linhagens estudado, a princípio, o primeiro cruzamento recomendado é SA-13 x TH-05, uma vez que a maior distância de Mahalanobis foi constatada entre essas linhagens, proporcionando a alocação das mesmas em grupos distintos pelos métodos de Tocher (TAB. 4) e UPGMA (FIG. 1). Além disso, as referidas linhagens possuem diferentes backgrounds genéticos. As linhagens SA-13 e
TH-05 possuem frutos grandes $(\geq 3,0 \mathrm{~kg})$, mas diferem principalmente na firmeza da polpa e no teor de sólidos solúveis.

A linhagem SA-13 pode ser cruzada com as linhagens do grupo II, preferencialmente com as linhagens TH-06 e TH-08 em razão da magnitude das distâncias de Mahalanobis (TAB. 2). As linhagens TH-06 e TH-08 são mais produtivas em relação à linhagem SA-13, mas a linhagem SA-13 tem maior firmeza de polpa e teor de sólidos solúveis superior a linhagem TH-06.

Em razão das magnitudes das distâncias, a linhagem SA-13 pode ser cruzada com as linhagens TH-03, TH-07, TH-09 e SA-17, pertencentes ao grupo I formado pelo método de Tocher. As referidas linhagens têm menor firmeza de polpa, teor de sólidos solúveis e frutos menores em relação à linhagem SA-13, mas são mais produtivas (TAB. 1). 


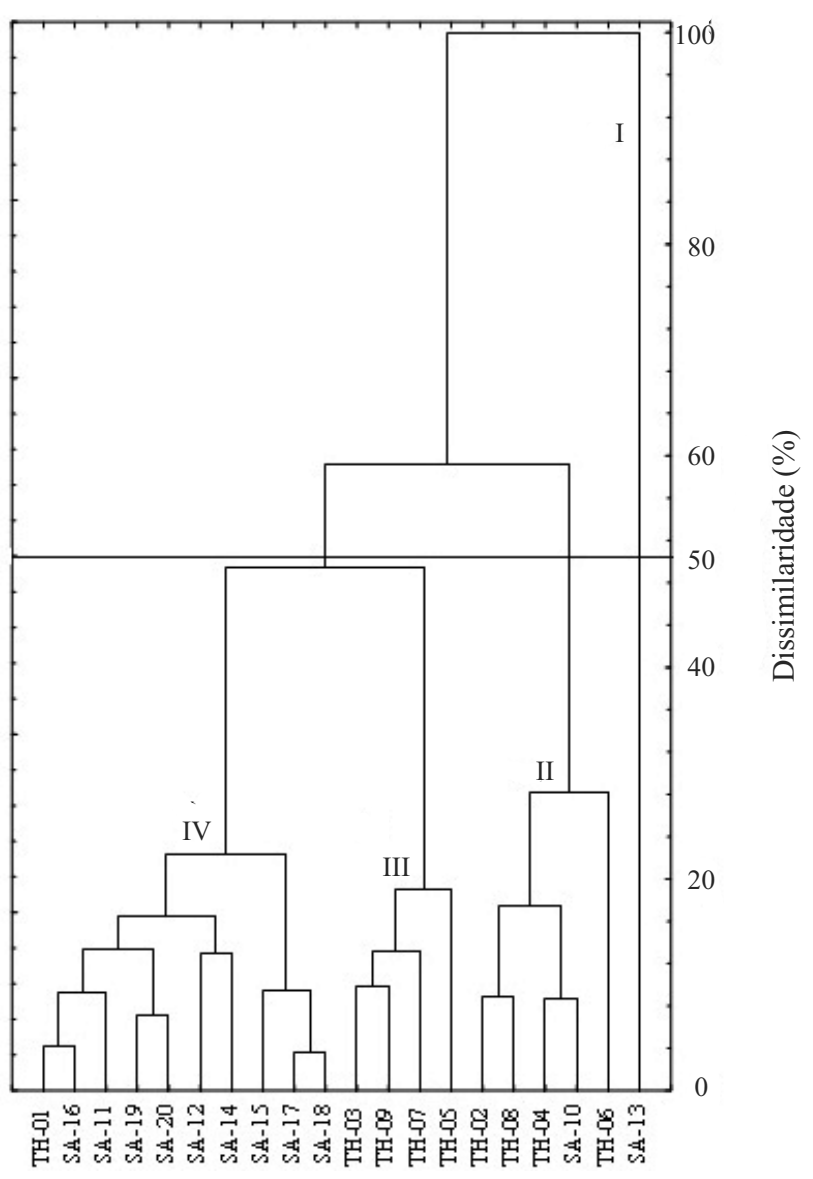

Figura 1 - Dendrograma baseado em UPGMA, obtido a partir das distâncias generalizadas de Mahalanobis de 20 linhagens de melão pele de Sapo avaliadas no município de Mossoró-RN. Mossoró-RN, 2005. (Correlação Cofenética $=0,76^{* *}$, Distorção $=15,16 \%$ )

Tabela 3 - Contribuição de cada característica para divergência genética pelo critério de Singh entre linhagens de melão Pele de Sapo avaliadas no município de Mossoró. Mossoró-RN, 2005

\begin{tabular}{lc}
\hline \multicolumn{1}{c}{ Característica } & $\begin{array}{c}\text { Contribuição para } \\
\text { divergência (\%) }\end{array}$ \\
\hline Número total de frutos por ha & 9,16 \\
Produtividade $\left(\mathrm{t} \mathrm{ha}^{-1}\right)$ & 8,05 \\
Peso médio do fruto $(\mathrm{kg})$ & 9,38 \\
Diâmetro transversal $(\mathrm{cm})$ & 3,89 \\
Diâmetro longitudinal $(\mathrm{cm})$ & 8,02 \\
Índice de formato & 8,85 \\
Cavidade interna (cm) & 7,44 \\
Espessura da polpa (cm) & 6,27 \\
Firmeza da polpa (N) & 20,69 \\
Sólidos solúveis $(\%)$ & 10,94 \\
Concentração de colheita $(\%)$ & 3,51 \\
Perda de peso $(\%)$ & 3,8 \\
\hline
\end{tabular}

A linhagem TH-05, a segunda mais divergente do grupo avaliado, poderia ser cruzada com as linhagens do grupo II, preferencialmente com SA-10 e TH-04, pelas magnitudes das distâncias de Mahalanobis (TAB. 2). A linhagem TH-05 maiores frutos, com maior espessura de polpa e cavidade. Qualidades que podem ser combinadas com a maior produção, maior firmeza de polpa e menor teor de sólidos solúveis das linhagens SA-10 e TH-04 (TAB. 1).

A linhagem TH-05 poderia ser cruzada com as linhagens SA-12, SA-20, SA-14 do grupo I. As maiores distâncias de Mahalanobis para as linhagens SA-12, SA20, SA-14 são em relação à linhagem TH-05 (TAB. 2). Os referidos cruzamentos permitem combinar as qualidades de número total de frutos, produtividade, sólidos solúveis, firmeza de polpa das linhagens SA-12, SA-20, SA-14 com o tamnaho do fruto da linhagem da linhagem TH-05.

Embora o procedimento mais indicado para testar a capacidade de cruzamentos de linhagens seja o testcross, especialmente em espécies com alta taxa de fecundação cruzada como o milho, as empresas produtoras de sementes têm recetemente utilizado a divergência genética com base em caracteres morfo-agronômicos e também com dados moleculares para identificar combinações de genitores com potencial para obtenção de populações segregantes com média elevada e grande variabilidade genética. Todavia, os estudos têm mostrado que não necessariamente os genitores mais divergentes produzirão a população com as características desejadas (FERREIRA et al., 1995). No caso do meloeiro, há resultados discrepantes na literatura. Paiva (2002) não constatou relação entre a divergência de linhagens e a heterose. Barros (2005) também trabalhando com melão verificou que não há associação entre a divergência e a variabilidade genética na população, bem como entre a divergência e a heterose. Todavia, trabalhando com a divergência genética com dados morfológicos e moleculres de linhagens de melão dos tipos Gália e Pele de Sapo, Garcia et al. (1998) recomendam a utilização das distancias genéticas para orientar cruzamentos em meloeiro e explorar a heterose, bem como José et al. (2005). Não obstante os resultados contraditórios verificados na literatura, vale ressaltar que o uso da divergência genética permite uma orientação parcial sobre quais cruzamentos podem ser realizados. Nesse sentido, as informações da divergência são interessantes, pois permitem a redução do trabalho do melhorista, bem como recursos e mão-deobra dispensados nos cruzamentos. No presente trabalho, o estudo da divergência genética permitiu maior indicação de cruzamentos de linhagens provenientes de backgrouds genético diferentes.

A análise de comparação de médias, juntamente com os agrupamentos estabelecidos pelo método de Tocher e UPGMA, permite a identificação de quais serão os cruzamentos promissores, bem como aqueles que poderão 
Tabela 4 - Agrupamento de 20 linhagens do tipo pele de Sapo conforme a metodologia de Tocher. Mossoró-RN, 2005

\begin{tabular}{clcl}
\hline \multirow{2}{*}{ Grupos } & \multicolumn{1}{c}{ Linhagens } & \multicolumn{1}{c}{ Distância média } \\
\cline { 3 - 4 } & \multicolumn{1}{c}{ SA-17, SA-18, SA-15, SA-16, SA-11, SA-19, TH-01, } & \multicolumn{1}{c}{ Intergrupo } \\
\hline I & SA-12, SA-20, SA-14, TH-02, TH-07, TH-03, TH-09 & 52,06 & DI, II $=103,88$ DI, III $=168,58$ \\
II & TH-04, TH-06, TH-08, SA-10 & 42,28 & DI, IV $=98,47$ \\
III & TH-05 & - & DIII, III $=163,68$ DII, IV $=399,08$ \\
IV & SA-13 & - & \\
\hline
\end{tabular}

resultar em variabilidade restrita nas gerações segregantes, como aqueles realizados entre progenitores de um mesmo grupo. Neste sentido, poderão ser esperadas como promissoras as seguintes hibridações: SA-13 x TH-03, SA$13 \times$ TH-04, SA-13 x TH-05, SA-13 x TH-07, SA-13 x TH09 e SA-13 x SA-17, TH-05 x TH-04, TH-05 x SA-10, TH05 x SA-12, TH-05 x SA-14 e TH-05 x SA-14.

\section{Conclusões}

1. Houve concordância parcial quanto à composição dos grupos formados pelos métodos de otimização de Tocher e UPGMA;

2. As características que mais contribuíram para a divergência foram firmeza de polpa $(20,69 \%)$ e sólidos solúveis $(10,94 \%)$;

3. A presença de variabilidade genética permitiu a identificação de cultivares dissimilares e com média elevada para as características estudadas;

4. Os cruzamentos sugeridos no estudo da divergência genética foram: SA-13 x TH-03, SA-13 x TH-04, SA13 x TH-05, SA-13 x TH-07, SA-13 x TH-09 e SA-13 x SA-17, TH-05 x TH-04, TH-05 x SA-10, TH-05 x SA12, TH-05 x SA-14 e TH-05 x SA-14.

\section{Rerefências}

BARROS, A. K. A. Análise dialélica entre cultivares de melão. 2005. 62 f. Dissertação (Mestrado em Fitotecnia) - Escola Superior de Agricultura de Mossoró, Mossoró.

BHERING, L. L. et al. Alternative methodology for ScottKnott test. Crop Breeding and Applied Biotechnology, v. 8, n. 01, p. 9-16, 2008.

BRAZ, L. T.; RIZZO, A. A. N.; CARDOSO, A. I. I. Divergência Genética entre genótipos de melão rendilhado para cultivo em ambiente protegido. Horticultura Brasileira, v. 22, p. 413, 2004.
CARMO FILHO, F.; OLIVEIRA, O. F. Mossoró: um município do semi-árido nordestino - características e aspectos florísticos. Mossoró: Fundação Guimarães Duque, 1989. 62 p. (Coleção Mossoroense, Série B)

CRUZ, C. D.; REGAZZI, A. J.; CARNEIRO, P. C. S. Modelos biométricos aplicados ao melhoramento genético. Volume 1.Viçosa: Editora UFV, 2004. 480 p.

CRUZ, C. D. Programa GENES: diversidade genética. Viçosa: Editora UFV, 2008. 278 p.

CRUZ, C. D.; CARVALHO, S. P. de.; VENCOVSKY, R. Estudos sobre divergência genética II. Eficiência de perdição do comportamento de híbridos com base na divergência de progenitores. Revista Ceres, v. 41, n. 234, p. 183-190, 1994.

DIAS, R. C. S. et al. Cadeia produtiva do melão. In: CASTRO, A. M. G. et al. Cadeias produtivas e sistemas naturais: prospecção tecnológicas. Brasília: SPI, 1998. p. 440-493.

FERREIRA, D. F. et al. Métodos de avaliação da divergência genética em milho e suas relações com os cruzamentos dialélicos. Pesquisa Agropecuária Brasileira, v. 30, n. 09, p. 1189-1194, 1995.

FILGUEIRAS, H. A. C. et al. Colheita e manuseio pós-colheita. In: FILGUEIRAS, H. A. C., MENEZES, J. B.; ALVES, R. E. Frutas do Brasil: melão pós-colheita. Brasília: Embrapa-SPI/ Frutas do Brasil, 2002. p. 23-41.

FREITAS, J. G. et al. Interação entre genótipo e ambiente em híbridos de melão amarelo no Nordeste do Brasil. Revista Ciência Agronômica, v. 38, n. 2, p. 176-181, 2007.

GARCIA, E. et al. Genetic relationships among melon breeding lines revealed by RAPD markers and agronomic traits. Theoretical and Applied Genetics, v. 96, p. 878-885, 1998.

GOMES JÚNIOR, J. et al. Caracterização pós-colheita de melão "Piel de Sapo", genótipo Imara, sob condições ambientes. Revista Brasileira de Fruticultura, v. 22, n. 01. p. 32-36. 2001.

GUSMINI, G.; WEHNER, T. C. Fifty-five Years of Yield Improvement for Cucumber, Melon, and Watermelon in the United States. HortTechnology, v. 18, n. 01, p. 9-12, 2008.

JOSÉ, M. A.; IBAN, E.; SILVIA, A.; PERE, A. Inheritance mode of fruit traits in melon: Heterosis for fruit shape and its correlation with genetic distance. Euphytica, v. 144, p. 31-38, 2005. 
LOPÉZ-SESÉ, A. I., STAUB, J. E., GOMEZ-GUILLAMON, M. L. Genetic analysis of Spanish (Cucumis meloL.) germplasm using a standardized molecular-marker array geographically diverse reference accessions. Theoretical Applied Genetics, v. 108, p. 41-52, 2003.

MACHADO, C. F. et al. Divergência genética entre genótipos de feijoeiro a partir de técnicas multivariadas. Ciência Rural, v. 32, n. 02, p. 251-258, 2002.

MALUF, W. R. Heterose e emprego de híbridos F1 em hortaliças. In: NASS, Luciano Lourenço et al. (Orgs.). Recursos Genéticos e Melhoramento-Plantas. Rondonópolis-MT: Fundação MT, 2001. p. 327-355.

MENEZES, J. B. et al. Armazenamento de dois genótipos de melão amarelo sob condições ambiente. Horticultura Brasileira, v. 19, n. 01, p. $42-49,2001$.

MONTGOMERY, D. C.; PECK, E. A. Introduction to linear regression analysis. New York: John Wiley, 1981. 504 p.

NUNES, G. H. S. et al. Aspectos produtivos e de qualidade de híbridos de melão cultivados no agropolo Mossoró-Assu. Horticultura Brasileira, v. 22, n. 04, p. 744-747, 2004.

NUNES, G. H. S. et al. Desempenho de híbridos do grupo inodorus em Mossoró. Horticultura Brasileira, v. 23, n. 01, p. 90-94, 2005.
PAIVA, W. O.; SABRY NETO, H.; LOPES, A. G. S. Avaliação de linhagens de melão. Horticultura Brasileira, v. 18, n. 02, p. 109-113, 2000.

PAIVA, W. O. Divergência genética entre linhagens de melão e a heterose de seus híbridos. Horticultura Brasileira, v. 20, n. 01, p. 34-37, 2002.

PAIVA, W. O. et al. Melão Tupã: origem e melhoramento genético. Fortaleza: Embrapa Agroindústria Tropical, 2004.

RIZZO, A.; BRAZ, L. T. Divergência genética entre cinco genótipos de melão rendilhado. Horticultura Brasileira, v. 20, n. 02, p. 171-173, 2002.

SALES JÚNIOR, R. et al. Aspectos qualitativos do melão exportado pelo porto de Natal-RN. Ciência Rural, v. 36, n. 02, p. 286-289. 2006.

STAUB, J. E., FANOURAKIS, N.; LOPEZ-SESÉ, A. I. Genetic diversity in melon (Cucumis melo L.) landraces from the island of Crete as assessed by random amplified polymorphic DNA and simple sequence repeat markers. Genetic Research Crop Evolution, v. 49, n. 01, p. 157-263. 2003.

TORRES FILHO, J. et al. Caracterização morfológica de acessos de meloeiro coletados no nordeste brasileiro. Revista Caatinga, v. 22, n. 03 , p. 174-181. 2009. 